\title{
9.6 Energy and Cost Efficiency in CNC Machining from a Process Planning Perspective
}

\author{
S Anderberg ${ }^{1}$, T Beno ${ }^{1}$, L Pejryd ${ }^{1,2}$ \\ ${ }^{1}$ University West, Department of Engineering Science, Trollhättan, Sweden \\ ${ }^{2}$ Production Technology Centre, Innovatum AB, Trollhättan, Sweden
}

\begin{abstract}
The role of process planning as an enabler for cost efficient and environmentally benign CNC machining is investigated in the paper. Specific energy is used as the principal indicator of energy efficient machining and different methods to calculate and estimate the specific energy is exemplified and discussed. The interrelation between process planning decisions and production outcome is sketched and how process capability can be considered as one factor of green machining is assessed. A correlation between total machining cost and total energy use is presented for an experimental machining case. A general conclusion is that in order to be able to draw general conclusions, the importance of having reliable data during process planning to make effective decisions is essential.
\end{abstract}

Keywords:

Cost efficiency, Energy efficiency, CNC machining, Green manufacturing, process planning

\section{INTRODUCTION}

Changing demands and requirements from customers, governmental regulations and changing competition impose partly new areas of competition for many companies. Today not only quality, flexibility, time and cost requirements are to be met, but also increasing demands on environmental impact. To achieve sustainable production, both demands of traditional economic focus as well as environmental must be fulfilled. For economic performance a variety of indicators are used based on cost, time and quality on different levels in the production system. It is essential to define criteria, indicators and methods to enable more environmentally benign production, in this work focused to CNC machining. Basically environmental improvements of CNC machining can be achieved through technology development or through the use of more effective methodologies. Process planning is vital for this move to take place. Zein et al. [1] listed 124 improvement measure for making energy saving in CNC machining. $40 \%$ of these relate to improved machine tool design while $22 \%$ measures relate to energy demand reduction through improved process design [1]. It is the latter $22 \%$ that relates to process planning and consequently being investigated in this work.

Decisions made during process planning, to a large extent dictates the production outcome, such as lead times, quality levels, process capability, but also energy use and the environmental impact of the goods production. Herrmann et al. [2] states that both green manufacturing and lean production share many similar basics, where the elimination of waste is the major commonality. Waste can basically be regarded as a consequence from low process capability.

Process planning is a key function to realise products that fulfil defined requirements. However, it is important to provide the right knowledge to process planners. It can be in the form of analytical models, data, experience, which can be spread through the use of best practice cases or workshops.
However, to achieve advancements that results in real reduction of environmental impacts, methods and strategies must be developed and communicated. It is in this aspect also important to add the economic aspects as well, to gain industrial acceptance. A previous study presented the effects that increasing electrical energy prices potentially can have on the total cost of $\mathrm{CNC}$ machining [3]. It concluded that electrical prices are not high enough to pose any particular need for making radical energy savings in CNC machining. However, real cost savings can be made as a consequence from time savings. If production output can be increased due to optimised machining parameters, cost and energy savings can concurrently follow. However, depending on the need for manual work in CNC machining, future increased costs of electricity can play an increasingly important role of the total machining cost. The trend towards increased automation (and the use of FMSs etc.) will accordingly cause cost of energy to stand for a larger proportion of the total machining cost.

\subsection{Process planning for sustainable CNC machining}

Sustainable production can in general be considered to include the following aspects, which in a significant way are influenced by decisions made during process planning:

- Cost (Labour, machine tools, cutting tools - as function of machining time)

- Environment (Energy use, materials and process emissions from usage of cutting fluids)

- Quality (Process capability, scrap rate, in process control needs etc.)

- $\quad$ Lead time (Material removal rates, reduced set-up times - hence decreased standby times)

- Flexibility (Routines, KBE, competence)

It is important to understand the interrelation between different machining factors, decisions, constraints etc. and their respective influence on the machining outcome. Fig. 4 
describes how four performance aspects - economic, environment, process capability, i.e. robustness during production and what is physically attainable.

\subsection{Research questions}

The following questions are investigated and discussed is this paper:

- How can process planning create more environmental friendly machining operations, in terms of energy use?

- Which are the main factors and what is their respective importance when designing $\mathrm{CNC}$ machining processes for energy efficiency?

- What are the analogies between process designs for cost efficiency versus energy efficient CNC machining with respect to machining parameters?

\section{SPECIFIC ENERGY AS ENERGY EFFICIENCY MEASURE}

There are principally two types of specific energy; one is the direct specific energy to remove material, which can be named specific energy on process level. This value describes the energy per volume unit required to physically form a chip and thus remove the material. Data on this specific energy can be found in handbooks, calculated analytically or measured by using piezo-electric dynamometers directly mounted on the cutting tool holder in turning operations or on the work table in a milling and drilling machines. In order to get a realistic energy use of the machine tool, this value must be corrected by assigning a corresponding specific energy or the efficiency $(\eta)$ for the machine tool. The specific energy on process level is calculated using eq. 1 , where $F_{c}$ is the cutting force, $b$ width of cut and $t$ the undeformed chip thickness (function of feed rate and entering angle).

However, the specific energy can also describe the energy that must be fed to the machine tool to remove material. Eq 2 expresses the specific energy when the machine tool power, $P$ is used. $P$ is divided with the MRR for the current operation. One problem with this value is that only the machining activities are regarded. Non-removing work (MRR $=0$ ) is not captured, which makes this measure most suitable to use when different operations are evaluated against each other.

To find the effective specific energy, that most comprehensively describe the whole machining process, the total energy, $\mathrm{E}$ (as can be extracted from a power/time plot) can be used, which is related to the total volume of removed material. This value will include all non-value adding activities necessary to machine the component (e.g. spindle start, repositioning of tool, enter and exit of cut etc.), see eq 3.

$$
u_{1}=\frac{F_{C}}{b \cdot t} \quad \text { (1), } \quad u_{2}=\frac{P}{M R R} \quad \text { (2), or } \quad u_{3}=\frac{E}{V}
$$

Fig. 1 provides an overview of the different methods to use in order to calculate the specific energy. Most relevant from an environmental perspective is to calculate the total energy use required to machine the intended feature. This means that only studying the cutting process isolated from other factors (i.e. machine, auxiliary systems) will not be sufficient. If the power is measured directly in the process (as described above), the value must be corrected to the specific machine specifications, which requires measured values of machine efficiency, machine supplier data on efficiency or estimates from tables or analytically derived. Kara and Li [4] developed machine tool models for different machine tools, which predicts the specific energy as a function of MRR. These models can be useful to estimate the actual energy use of a machining process during process planning to evaluate different machining strategies. However, since machine tools are complex, with many subsystems, a generic machine tool model is difficult to derive. To this adds the many possible combinations of materials, machining parameters, use of different amounts of cutting fluids etc. which makes modelling complex.

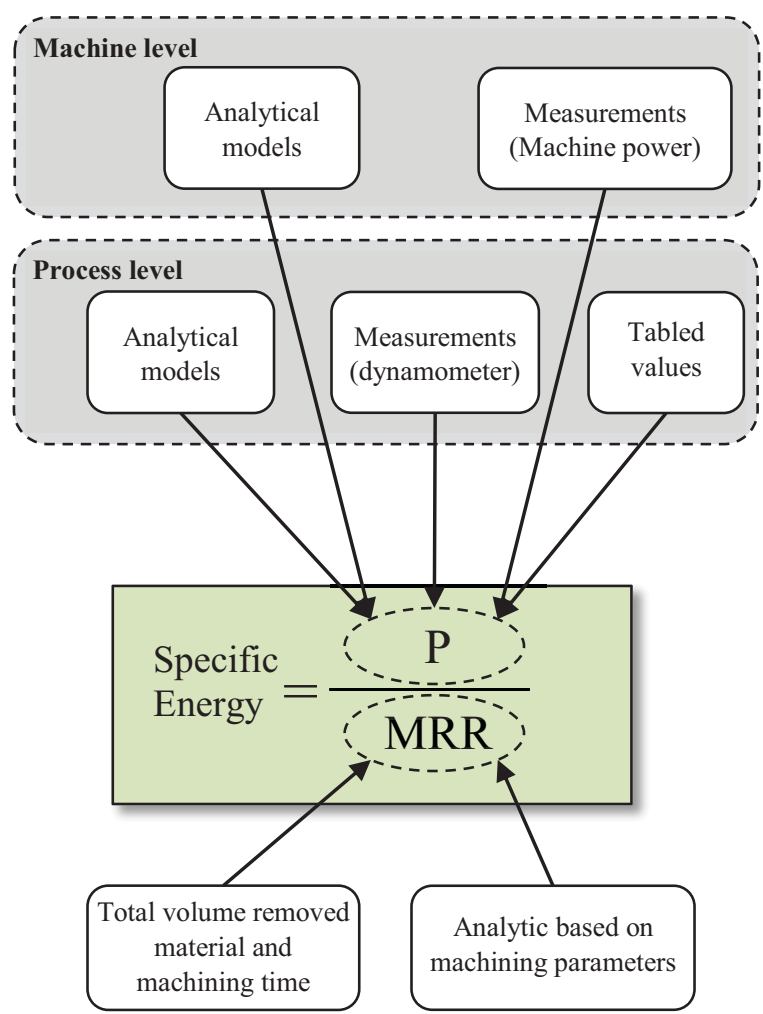

Fig. 1 : Overview of different methods to calculate specific energy.

Roughing (and roughing with surface finish demands) and finishing influence the possibilities for green machining, since surface roughness requirements constrains the machining process, i.e. higher MRRs are not allowed, especially high feed rates. Due to the behaviour of the specific energy as a function of MRR, where the hyperbola curve flattens out towards higher MRR, the full potential of machining with high MRR and limiting the increase rate of specific energy cannot be utilised. It is however difficult to generalise the possibilities, since it depends on the actual surface finish requirements and the governing parameters of specific energy. 


\section{RESULTS AND DISCUSSION}

From a process planning perspective it is efficient to have reliable knowledge repositories where data regarding tooling, machining parameters, machine capability, and in a green machining perspective also data regarding machine tool power profile, material data (specific energy), embodied cutting tool energy to be able to make effective and informed decisions. Process planning performed by humans, which is the dominating mode in the industry does not differ from more computer-based approached to process planning (e.g CAPP), since no matter what mode of process planning, the need for accurate and reliable data is the fundaments to enable effective decisions.

The most effective indicator of green machining is the total energy used by the machine tool and necessary auxiliary equipment in relation to the volume of total removed material volume, which in effect is specific energy.

As discussed in the introduction, to be able to make effective decisions during process planning it is vital to have accurate data and information. The following sections aim at highlighting a few areas which are of importance, where results are achieved, but more research activities are needed as well so that generic conclusions can be drawn.

\subsection{Results from modelling machining cost and energy use}

Results from the experiments (shortly described hereunder) to test the machining cost model (see ref. [5]) showed that it is not the cost of energy that is governing energy efficiency improvements, but better utilisation of the machine and increased production rate. These are important learnings for the process planner when optimising the machining process for environmental impact as well as minimised production costs.

The model is based on handbook formulas for machining cost estimations, but extended with costs for direct and indirect energy consumption. Experimental data was gathered from turning a simple part of mild carbon steel using different machining strategies, where the machine power and tool wear were measured. The different strategies include alternated feed rates and depths of cuts. The model and results are more in depth presented in ref. [5].

The same model is used here as the fundament for the analysis, but extended to also include the embodied energy use for manufacturing the cutting tool insert, which was omitted in the first study. The first study gave the result that the most energy efficient machining was found towards higher MRR, no local minimum was found to exist as was for the machining cost. This analysis perspective can be defended since it corresponds to the situation where the workshop itself is isolated from the overall supply chain, where the energy use is quantified only based on the electric power from the socket. In order to widen the scope to also study the general environmental impact from machining operations, this approach has its limits, since the environmental aspect of tool wear must be included as well, since excessive tool wear must be considered to constitute a negative impact on the environment, not only cost. The total embodied energy in cutting tools was modelled by using figures from Dahmus and Gutowski [6] where the carbide production was stated to require $400 \mathrm{MJ} / \mathrm{kg}$ and different coating techniques (PVD,
$P C D)$ require 1-2 MJ per coating process and insert. With a weight of $4.0 \mathrm{~g}$ for the insert used in the experiments, the embodied energy in the cutting tool is found to be 0.60 $\mathrm{kJ} /$ edge (with an insert of 6 cutting edges and if the higher value is used). The result is plotted in Fig. 2. With increasing embodied energy in relation to MRR, the total electrical energy use curve will move towards the left side. With decreasing embodied energy, and possibilities for higher MRR, the curve will instead move towards the right, more resembling the specific energy curve of machining operations.

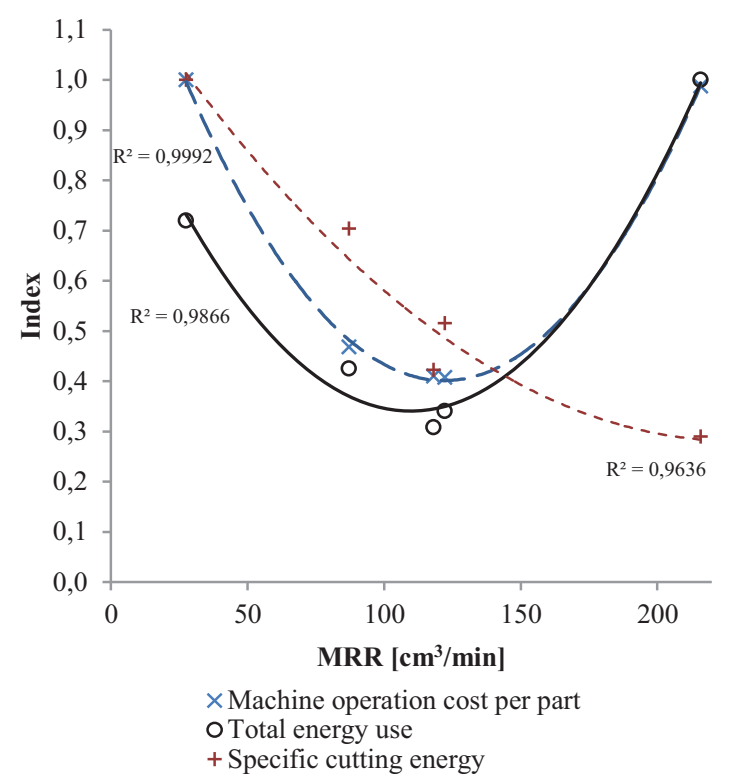

Fig. 2 : Relation between machining cost, total environmental energy use, specific cutting energy. 
Tab. 1 : Machining factors and their relative importance on energy use (Values are based on handbooks, scientific papers etc. and formatted to fit the unit $\mathrm{kJ} / \mathrm{cm} 3$ ).

\begin{tabular}{|c|c|c|c|c|c|}
\hline $\begin{array}{c}\text { Factor } \\
\text { Specific energy }\end{array}$ & Machine tool & Workpiece material & $\begin{array}{l}\text { Machining } \\
\text { parameters }\end{array}$ & Cutting tool & $\begin{array}{l}\text { Auxiliary } \\
\text { equipment }\end{array}$ \\
\hline $\begin{array}{l}\text { Factor ratio } \\
\text { [max/min of nominal } \\
\text { values] }\end{array}$ & $\sim 7$ & $\sim 7$ & $\sim 3$ & $\sim 2$ & $\sim 10$ \\
\hline \multirow[t]{5}{*}{$\begin{array}{l}\text { Observed typical } \\
\text { nominal values }\end{array}$} & $\begin{array}{c}\text { 0.74- } 5.45\left[\mathrm{~kJ} / \mathrm{cm}^{3}\right] \\
\text { (standby milling) } \\
\text { ref. [4] }\end{array}$ & $\begin{array}{c}2.1-2.8\left[\mathrm{~kJ} / \mathrm{cm}^{3}\right] \\
\text { (low alloy steel) ref. [7] }\end{array}$ & $\begin{array}{c}1.5-4.0\left[\mathrm{~kJ} / \mathrm{cm}^{3}\right] \\
\text { (SS 1450) ref. [7] }\end{array}$ & $\begin{array}{c}\text { 4.8- } 7.3\left[\mathrm{~kJ} / \mathrm{cm}^{3}\right] \\
\text { (diff. rake angles) } \\
\text { ref. [8] }\end{array}$ & $\begin{array}{c}1-10\left[\mathrm{~kJ} / \mathrm{cm}^{3}\right] \\
\text { (5.6- } 9.5[\mathrm{~kW}] \text { sum } \\
\text { aux. syst.) ref. [9] }\end{array}$ \\
\hline & $\begin{array}{c}1.16-1.77\left[\mathrm{~kJ} / \mathrm{cm}^{3}\right] \\
\text { (standby lathes) } \\
\text { ref. }[4]\end{array}$ & $\begin{array}{l}1.1-1.8\left[\mathrm{~kJ} / \mathrm{cm}^{3}\right] \\
\text { (cast iron) ref. [7] }\end{array}$ & $\begin{array}{c}1.9-4.8\left[\mathrm{~kJ} / \mathrm{cm}^{3}\right] \\
\text { (SS 2244) ref. [7] }\end{array}$ & $\begin{array}{c}20.8-23.3\left[\mathrm{~kJ} / \mathrm{cm}^{3}\right] \\
\text { (micro milling) } \\
\text { ref. [10] }\end{array}$ & \\
\hline & & $\begin{array}{c}2.3-3.0\left[\mathrm{~kJ} / \mathrm{cm}^{3}\right] \\
\text { (stainless steel) ref. [7] }\end{array}$ & $\begin{array}{c}\text { 1.8- } 3.2\left[\mathrm{~kJ} / \mathrm{cm}^{3}\right] \\
\text { (SS 1550) ref. [7] }\end{array}$ & & \\
\hline & & $\begin{array}{c}3.0-3.7\left[\mathrm{~kJ} / \mathrm{cm}^{3}\right] \\
\text { (heat res. alloys) } \\
\text { ref. [7] }\end{array}$ & & & \\
\hline & & $\begin{array}{c}0.5-1.0\left[\mathrm{~kJ} / \mathrm{cm}^{3}\right] \\
\text { (Aluminium) ref. [7] }\end{array}$ & & & \\
\hline
\end{tabular}

\subsection{Capability and level of quality}

The level of quality is vital for the overall environmental impact of machining operations. A scrap rate of $10 \%$, will lead to an overproduction of the same proportion, with all the environmental impact that the machining operation has. Quality problems in machining operations stem form a number of causes, e.g. excessive tool wear, chip breaking, vibrations etc. Astakhov [11] states that ensuring reliability of cutting tools are important from a cost perspective, since it reduces cycle times, human errors and need for rework. The same holds true from an environmental perspective as well.

As was stated in the introduction, waste is the result of poor process capability and can be caused by inappropriate machine choice for the current part, tooling, machining parameters, clamping etc. All of these factors results in unnecessarily high scrap rates or rework rates. In this perspective the use of process capability indices (PCls), such as $C_{p}$ and $C_{p k}$ can be indicators of environmental performance alongside quality levels and performance of the production system.

Fig. 4 illustrates the relations between different aspects of machining outcome in relation to process planning decisions on machine tool, tooling, machining parameters. It is clear from this figure that many aspects of machining are interrelated. Where e.g. low process capability definitely influences both quality levels, overall process cost as well as the environmental impact. More in depth analysis of process capability from a process planning is found in Anderberg et al. [12].

\subsection{Different machining factors' impact on specific energy}

As mentioned in the introduction, specific energy is chosen as an indicator of environmental performance of machining operations. However, it can be confusing and difficult to relate various factors influence of the total specific energy for a certain machining operation. Tab. 1 compiles values of the most important factors governing the magnitude of the total specific energy. The objective of the table is to create an overview of the ruling factors and their variation in contributing to the magnitude of the specific energy, which can be helpful when different options are being considered during process planning. It also aims at illustrating the complexity and the importance of having reliable data for the current machining set-up, since the resulting process can require a significantly higher energy use if some the factors are overlooked. As seen, to only regard the machine tool and neglect the workpiece material can lead to erroneous decisions, since the specific energy to remove different types of materials can approximately vary by a factor 7 . Likewise to neglect machining parameters' influence on specific energy can lead to poor process designs, both from cost and energy efficiency perspectives.

Interesting to note is that extremely high values of specific energies can be reached when machining at extremely low MRR. This is the case for micro machining [10] and machining of difficult materials such as Inconel 718 , which could generate 12 fold ratios (as is seen in Beno et al. [13]).

The values in the table are based on published works and the compilation should by no means be considered complete. However, the tendencies should be representative for the actual situation. The factor ratio describes the 
uncertainty and can be interpreted as a worst case scenario that if the factor is overlooked, its intrinsic effect can change by a factor (e.g. 2, 3 or 7 ). The respective importance of each factor's influence of the total specific energy use for a specific operation is difficult to generalise, since it depends on the type of operation (micro machining, finishing, roughing etc.) where the machine tool in some of these cases stands for the proportionally large part. The factor ratio is calculated as the ratio between the largest and smallest value in each respective column. Each column describes typical values for each factor, where for the workpiece material states different materials, and within each type of material the typical specific energy values are stated, e.g. low alloy steels nominally range between 2.1 and $2.8 \mathrm{~kJ} / \mathrm{cm}^{3}$.

From the above, the conclusion can be drawn, that in order to make effective decision during process planning, accurate data is important. Otherwise faulty decisions are likely.

\subsection{A green machining strategy}

In order for the industry and the individual company to advance towards more environmental friendly production, a green machining strategy should be developed. Fig. 3 shows how such a strategy can be designed and here illustrated for the industry at large in the perspective of process planning and research and development initiatives both in academia and industry. The parameters that can be influenced mainly by the process planner are located on the left side. To work with these aspects is more of picking the low hanging fruit, but as shown in various models and experiments, the achievements can be considerable; hence these efforts should not be overlooked. Towards the right side of Fig. 3, more research and development of equipment must be carried out in order to achieve results.
Some activities are joint efforts, as can be seen by the overlaps and some results are more immediate, whereas other can only be acquired through future development work. As has been highlighted in this paper and other papers on the topic, there are many things to do as a process planner to move towards green machining, which do not require extensive efforts to be achieved.

\subsection{Further research efforts}

From the above reasoning, a number of difficulties were discussed, which need further research efforts before effective solutions can be presented:

- More accurate data on the factors that constitute the specific energy are needed, which can be based on experimental data or analytical models (which today are often complex and non-generic).

- Material databases (specific energy as a function of machining parameters, preferably in the form of $3 \mathrm{D}$ surfaces for feed and cutting speed as presented in [13])

- $\quad$ Dry and near dry machining solutions can potentially decrease the specific energy, but further work is needed to understand the real savings (environmental and cost wise) and which are the trade-offs in the form of surface roughness problems, tool wear, process capability etc.

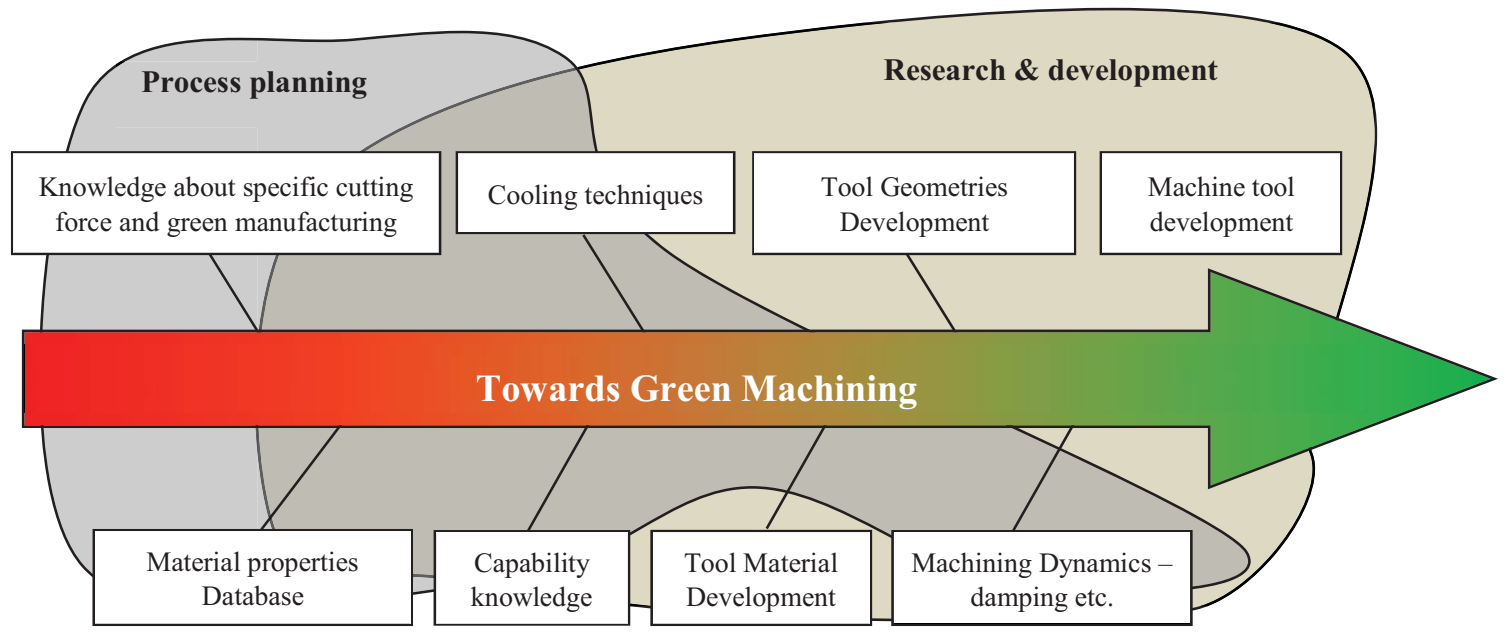

Fig. 3 : A green machining strategy. 


\section{CONCLUSIONS}

A number of areas of CNC machining for cost and energy effectiveness have been highlighted and discussed from mainly a process planning perspective. Specific energy was used as the principal indicator of energy efficiency and greenness of machining operations. The following issues were raised in the paper:

- The relations between different machining outcomes in relation to process planning decisions.

- A correlation between total machining cost and total energy use was shown for an experimental case.

- The importance of having reliable data to predict machining outcome, which was indicated by compiling observed values of specific energy in relation to different influencing factors.

- The Process capability's influence on green machining.

- A green machining strategy was presented as a mean to enable a move towards more environmentally benign machining.

\section{REFERENCES}

[1] Zein, A., et al. (2011) Energy efficiency measures for the design and operation of machine tools: An axiomatic approach, Proceedings of the 18th CIRP International Conference on Life Cycle Engineering, Braunschweig, Germany

[2] Herrmann, C., et al. (2008) An environmental perspective on Lean Production, Proceedings of the 41th CIRP International Conference on Manufacturing Systems, May 26 - 28, Tokyo, Japan

[3] Anderberg, S. and Kara, S. (2009) Energy and cost efficiency in CNC machining, 7th Global Conference on Sustainable Manufacturing, Madras, India
[4] Kara, S. and Li, W. (2011) Unit process energy consumption models for material removal processes. CIRP Annals - Manufacturing technology, 60.

[5] Anderberg, S., et al. (2010) Impact of energy efficiency on computer numerically controlled machining. Journal of Engineering Manufacture (Part B), 224(B4): p. 531541.

[6] Dahmus, J., B. and Gutowski, T., G. (2004) An Environmental Analysis of Machining, 2004 ASME International Mechanical Engineering Congress and RD\&D Expo, Anaheim, California, USA

[7] Wiiburg-Bonde, E. (2000) Karlebo handbok, Karleboserien, Liber, Stockholm,

[8] Trent, E., M. and Wright, P., K. (2000) Metal Cutting, Butterworth Heinemann, Boston, 978-0-7506-7069-2

[9] (2010) Aspects of energy efficiency in machine tools, http://www.heidenhain.com/fileadmin/pdb/media/img/En ergieeffizienz_WZM_en.pdf, [cited 2011-08-01]

[10] Diaz, N., et al. (2011) Energy consumption characterization and reduction strategies for milling machine tool use, Proceedings of the 18th CIRP International Conference on Life Cycle Engineering, Braunschweig, Germany

[11] Astakhov, V.P. (2010) Cutting Tool Sustainability. Sustainable Manufacturing, ed. Davim, J.P. Wiley-ISTE: London, 9781848212121

[12] Anderberg, S., et al. (2011) Process Planning for CNC Machining from a capability perspective. (submitted).

[13] Beno, T., et al. (2009) Green machining - Improving the bottom line, 16th CIRP International Conference on Life Cycle Engineering, Cairo, Egypt 


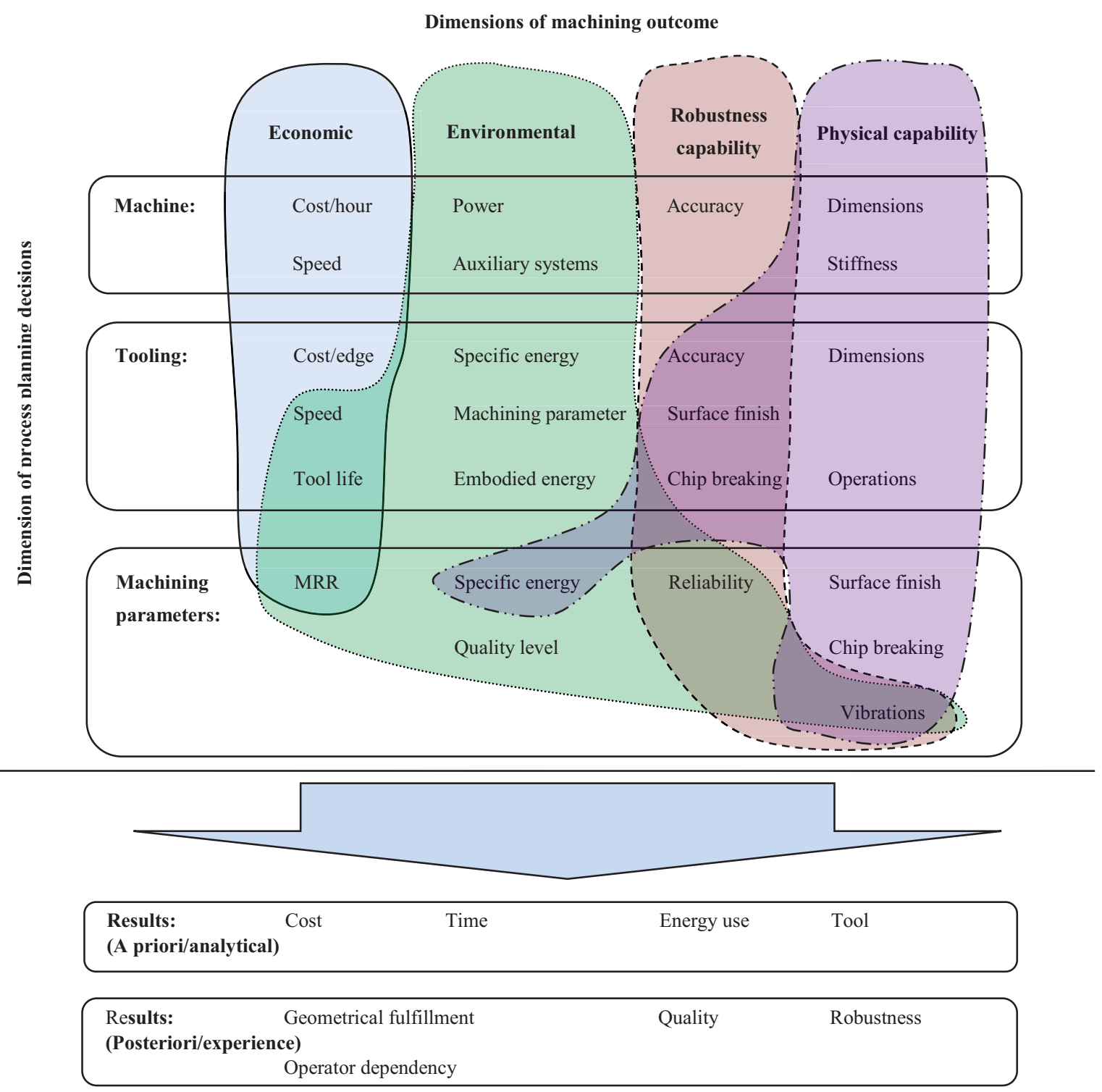

Fig. 4 : Relations between process planning decisions and machining outcome. 